(2) Open Access Full Text Article

\title{
New-onset ascites as a manifestation of virologic relapse in patients with hepatitis $\mathrm{C}$ cirrhosis
}

This article was published in the following Dove Press journal:

Hepatic Medicine: Evidence and Research

29 January 2014

Number of times this article has been viewed

\author{
Deborah Lim Chua \\ Thomas Hahambis \\ Samuel H Sigal \\ Division of Gastroenterology, \\ Department of Medicine, New York \\ University School of Medicine, \\ New York, NY, USA
}

Correspondence: Samuel Sigal

Division of Gastroenterology,

Department of Medicine, New York

University School of Medicine,

530 First Avenue - Suite 4J, New York,

NY I00I6, USA

Tel +I 2122633643

Fax + I 212263375

Email samuel.sigal@nyumc.org
Background: Chronic hepatitis $\mathrm{C}$ is the most common cause of cirrhosis in industrialized countries. Successful treatment of chronic hepatitis C in patients with advanced fibrosis or cirrhosis has significant benefits, including improvements in inflammation, fibrosis, and portal hypertension, with prevention of esophageal varices and clinical decompensation.

Case: In this report, we present two patients with well-compensated hepatitis $\mathrm{C}$ cirrhosis who achieved an end-of-treatment response on a direct-acting antiviral therapy-based triple regimen for hepatitis $\mathrm{C}$ virus, but subsequently presented with new-onset ascites associated with virologic relapse.

Conclusion: We propose that the development of ascites in this setting is due to the adverse impact of inflammation of the virologic relapse on portal hypertension. Our observation that ascites formation can be a manifestation of virologic relapse has potentially important clinical implications, as it highlights not only the importance of close monitoring of cirrhotic patients after achieving end-of-treatment response but also the impact of active inflammation on the severity of portal hypertension.

Keywords: chronic hepatitis C, cirrhosis, virologic relapse, portal hypertension, ascites

\section{Introduction}

Chronic hepatitis $\mathrm{C}$ (CHC) is currently the most common cause of cirrhosis in industrialized countries. In the US, there are currently approximately 4 million $\mathrm{CHC}$-infected people, and it is projected that 1.76 million with untreated $\mathrm{CHC}$ will develop cirrhosis over the next 40-50 years. ${ }^{1}$ Successful treatment of CHC has significant benefits. In advanced fibrosis or cirrhosis, sustained virologic response (SVR) has been shown to be associated with improved inflammation and fibrosis within 6 months after therapy compared to relapsers and nonresponders. ${ }^{2}$ In a retrospective study of CHC patients who achieved SVR, 56\% had improved fibrosis stage within 3 years, and $64 \%$ of cirrhotic patients had fibrosis regression to stages $1-3 .^{3}$

In compensated cirrhotic patients undergoing antiviral therapy, SVR is associated with improved portal hypertension. Significant decrease in the hepatic venous pressure gradient was seen in cirrhotic patients achieving SVR compared to those who did not respond. ${ }^{4}$ Achievement of SVR also prevents the development of esophageal varices and clinical decompensation. ${ }^{5,6}$ Among $\mathrm{CHC}$ patients with advanced hepatic fibrosis, SVR is associated with lower all-cause mortality, liver-related mortality, and need for transplantation. ${ }^{7}$

In this report, we describe two well-compensated cirrhotic patients who achieved end-of-treatment response on a direct-acting antiviral therapy-based triple regimen. 
Both presented after completing therapy with new-onset ascites and virologic relapse. Due to the adverse impact of inflammation on portal hypertension, we speculate that the sudden onset of inflammatory activity associated with relapse contributed to the development of ascites.

\section{Case I}

A 53-year-old woman with CHC genotype 1, biopsy-proven cirrhosis, and previous partial response to polyethylene glycosylated (PEGylated) interferon and ribavirin was started on telaprevir-based therapy. Cirrhosis was well compensated, without ascites or edema before and during therapy. Pretreatment laboratory evaluation revealed albu$\min 4.4 \mathrm{~g} / \mathrm{dL}$, aspartate aminotransferase (AST) $115 \mathrm{U} / \mathrm{L}$, alanine aminotransferase (ALT) $120 \mathrm{U} / \mathrm{L}$, alkaline phosphatase $191 \mathrm{U} / \mathrm{L}$, total bilirubin $1.1 \mathrm{mg} / \mathrm{dL}$, hemoglobin $16.3 \mathrm{~g} / \mathrm{dL}$, platelet count $183,000 / \mu \mathrm{L}$, and hepatitis $\mathrm{C}$ virus (HCV) viral load 3,210,000 IU/mL. Upper endoscopy was negative for varices. Therapy was complicated by anemia requiring ribavirin dose reduction and erythropoietin therapy and rash that resolved after discontinuation of telaprevir. Viral load was $110 \mathrm{IU} / \mathrm{mL}$ at treatment week three and undetectable at week eight. PEGylated interferon and ribavirin were discontinued after 48 weeks of therapy. HCV viral load remained undetectable from week eight until the end of therapy. Laboratory evaluation at week 45 revealed albumin $2.7 \mathrm{~g} / \mathrm{dL}$, AST $125 \mathrm{U} / \mathrm{L}$, ALT $67 \mathrm{U} / \mathrm{L}$, total bilirubin $1.3 \mathrm{mg} / \mathrm{dL}$, hemoglobin $10.1 \mathrm{~g} / \mathrm{dL}$, and platelet count $49,000 / \mu \mathrm{L}$. Weight at the end of therapy was $132 \mathrm{lb}(60 \mathrm{~kg})$. One month after discontinuation of therapy, the patient presented with $5 \mathrm{lb}$ weight gain (weight $137 \mathrm{lb}$ ) and newonset ascites. Evaluation revealed albumin $3.1 \mathrm{~g} / \mathrm{dL}$, AST $77 \mathrm{U} / \mathrm{L}$, ALT $44 \mathrm{U} / \mathrm{L}$, total bilirubin $0.8 \mathrm{mg} / \mathrm{dL}$, blood urea nitrogen $(\mathrm{BUN}) 8 \mathrm{mg} / \mathrm{dL}$, creatinine $0.7 \mathrm{mg} / \mathrm{dL}$, hemoglobin $13.5 \mathrm{~g} / \mathrm{dL}$, platelet count $105,000 / \mu \mathrm{L}$, and virologic relapse with HCV viral load of $228 \mathrm{IU} / \mathrm{mL}$. Abdominal magnetic resonance imaging (MRI) revealed a cirrhotic morphology, abdominal ascites, and recanalization of the umbilical vein and left retroperitoneal varices consistent with portal hypertension. The patient refused diagnostic paracentesis. An echocardiogram was obtained, which revealed normal left ventricular systolic and diastolic functions and right ventricular systolic pressure, with no sign of pulmonary hypertension. Ascites rapidly responded to sodium-restricted diet and diuretic therapy (spironolactone $50 \mathrm{mg}$, furosemide $20 \mathrm{mg}$ daily). Repeat laboratory evaluation after control of ascites revealed an albumin level of $3.9 \mathrm{~g} / \mathrm{dL}$. Repeat viral load 3 months after the end of therapy was 528,810 IU/mL.
Repeat abdominal MRI 7 months after therapy cessation showed no ascites.

\section{Case 2}

A 61-year-old woman with CHC genotype 1, biopsy-proven cirrhosis, and previous nonresponse to three courses of interferon-based therapy was started on telaprevir-based therapy. Cirrhosis was well compensated, without evidence of ascites or hepatic encephalopathy. Upper endoscopy was negative for esophageal varices. Laboratory evaluation revealed albumin $2.7 \mathrm{~g} / \mathrm{dL}$, AST $132 \mathrm{U} / \mathrm{L}$, ALT $81 \mathrm{U} / \mathrm{L}$, alkaline phosphatase $394 \mathrm{U} / \mathrm{L}$, total bilirubin $0.8 \mathrm{mg} / \mathrm{dL}$, hemoglobin $13.3 \mathrm{~g} / \mathrm{dL}$, platelet count $156,000 / \mu \mathrm{L}$, and $\mathrm{HCV}$ viral load 71,600 IU/mL.

After initiation of telaprevir-based therapy, the patient achieved rapid virologic response. Side effects of therapy included anemia, requiring ribavirin dose reduction and erythropoietin therapy. Treatment was noteworthy for stable hypoalbuminemia, with albumin level $2.1 \mathrm{~g} / \mathrm{dL}$ without edema or ascites. She completed 12 weeks of telaprevir-based therapy, but therapy was discontinued at treatment week 31 due to a severe facial rash requiring systemic steroids for 2 days. HCV viral load remained undetectable from treatment week four until the end of therapy. Laboratory evaluation at the end of therapy revealed albumin $2.1 \mathrm{~g} / \mathrm{dL}, \mathrm{AST}$ $64 \mathrm{U} / \mathrm{L}$, ALT $32 \mathrm{U} / \mathrm{L}$, alkaline phosphatase $347 \mathrm{U} / \mathrm{L}$, total bilirubin $1.3 \mathrm{mg} / \mathrm{dL}$, hemoglobin $10.8 \mathrm{~g} / \mathrm{dL}$, and platelet count $80,000 / \mu \mathrm{L}$. Weight at the end of therapy was $122 \mathrm{lb}$.

The patient presented 1 month later with $8 \mathrm{lb}$ weight gain (weight $130 \mathrm{lb}$ ) over 2 weeks, new ankle edema, and abdominal distention. Abdominal ultrasound showed moderate ascites. HCV viral load was undetectable, albumin $2.9 \mathrm{~g} / \mathrm{dL}$, AST $71 \mathrm{U} / \mathrm{L}$, ALT $37 \mathrm{U} / \mathrm{L}$, alkaline phosphatase $309 \mathrm{U} / \mathrm{L}$, total bilirubin $1.5 \mathrm{mg} / \mathrm{dL}$, BUN $13 \mathrm{mg} / \mathrm{dL}$, and creatinine $0.7 \mathrm{mg} / \mathrm{dL}$. The patient refused diagnostic paracentesis. An echocardiogram was obtained, which revealed normal left and right ventricular function, with no sign of pulmonary hypertension. Sodium-restricted diet and diuretics (spironolactone $50 \mathrm{mg}$, furosemide $20 \mathrm{mg}$ daily) were started, with prompt resolution of edema and ascites. Three months after the end of therapy, HCV viral load was $203 \mathrm{IU} / \mathrm{mL}$, and on repeat $69,900 \mathrm{IU} / \mathrm{mL}$, confirming relapse. Albumin level was $2.6 \mathrm{~g} / \mathrm{dL}$, AST $91 \mathrm{U} / \mathrm{L}$, ALT $55 \mathrm{U} / \mathrm{L}$, alkaline phosphatase $348 \mathrm{U} / \mathrm{L}$, total bilirubin $1.1 \mathrm{mg} / \mathrm{dL}, \mathrm{BUN} 12 \mathrm{mg} / \mathrm{dL}$, creatinine $0.6 \mathrm{mg} / \mathrm{dL}$, hemoglobin $13.5 \mathrm{~g} / \mathrm{dL}$ and platelet count $140,000 / \mu \mathrm{L}$. Diuretics were tapered, then discontinued at posttreatment week 20 with continued control of ascites. Albumin level remained stable at $2.6 \mathrm{~g} / \mathrm{dL}$. 


\section{Discussion}

Well-compensated cirrhosis was present in both patients prior to interferon-based therapy. Except for the expected side effects of therapy, both patients tolerated therapy and were free of ascites throughout therapy. Both developed ascites within 1 month of discontinuation of therapy. Both patients were on no other medications and had no other medical problems. Besides weight gain, abdominal distention, and ankle edema, neither patient had any other symptoms, including abdominal pain, fever, shortness of breath, or cough. In the first patient, virologic relapse was immediately detected. The viral load was only $228 \mathrm{IU} / \mathrm{mL}$ at the onset of ascites and subsequently rose to $528,810 \mathrm{IU} / \mathrm{mL}$ by 3 months posttreatment. In the second patient, serum $\mathrm{HCV}$ ribonucleic acid (RNA) was undetectable at the onset of ascites, but was subsequently detected.

Inflammation plays a significant role in the development and maintenance of portal hypertension. In chronic hepatitis B, inflammation is associated with increased liver stiffness, which predicts the presence of portal hypertension in chronic liver disease. ${ }^{12,13}$ Liver stiffness, which correlates with portal pressures in patients with recurrent hepatitis $\mathrm{C}$ following liver transplantation, has been reported to be increased by active inflammation.

Treatment of active inflammation in cirrhotic patients due to alcohol, hepatitis B, and autoimmune-mediated injury leads to a decrease in the severity of portal hypertension and marked clinical improvement. Portal hypertension, assessed by the hepatic venous pressure gradient, is higher in patients with alcoholic cirrhosis with concurrent acute alcoholic hepatitis than in patients without acute alcoholic hepatitis, ${ }^{14}$ and corticosteroid therapy leads to marked clinical improvement. Similarly, patients with end-stage liver disease secondary to chronic autoimmune hepatitis and hepatitis B may demonstrate marked clinical improvement following appropriate therapy. Although fibrosis may regress with effective therapy, it occurs over a prolonged period. The time course of clinical improvement and decrease in portal hypertension is more closely associated with resolution of inflammatory activity. In contrast, the acute development of inflammation superimposed upon chronic disease, such as superinfection of well-compensated cirrhotic patients with hepatitis E, frequently leads to rapid clinical decompensation. ${ }^{15}$

Despite the benefits of SVR in CHC cirrhosis, interferon-based therapy is associated with significant risk. In a retrospective analysis of cirrhotic patients awaiting liver transplantation, treated patients had significantly higher rates of bacterial infections and septic shock compared to controls, ${ }^{16}$ and $13 \%$ of patients treated with eltrombopag for thrombocytopenia to enable treatment with PEGylated interferon and ribavirin developed hepatic decompensation events (mostly ascites) during therapy. ${ }^{17}$ Recently, it has been reported that up to $4.4 \%$ of cirrhotic patients receiving telaprevir or boceprevir with PEGylated interferon and ribavirin will experience hepatic decompensation during therapy. ${ }^{18}$ The mechanism for the development of ascites during therapy remains to be determined. However, the development of hypoalbuminemia leading to decreased oncotic pressure is a possible factor. ${ }^{19}$

The development of ascites in our patients with initial virologic response was unexpected, due to the early beneficial effects of successful therapy on portal pressures. ${ }^{4}$ Although at the end of therapy aminotransferase levels remained elevated in both patients, the level of aminotransferase levels is poorly correlated with inflammatory activity in $\mathrm{CHC} .{ }^{10}$ Levels during therapy with telaprevir and PEGylated interferon may remain elevated despite a virologic response in up to $67 \%$ of patients with elevated ALT levels at baseline. ${ }^{11}$ Although levels decrease to a greater extent compared to placebo in patients treated with telaprevir-based therapy, no information is available on the percentage of normalization and its correlation with SVR at the end of therapy.

Hypoalbuminemia has been found to be a predictor of development of adverse events during triple therapy. Although the development of hypoalbuminemia may have predisposed our patients to ascites, it was not due to the adverse effects of active therapy, as both first developed this complication one month after therapy had been discontinued. Rather, we propose that the development of ascites after completion of therapy was due to the adverse impact of acute inflammation associated with virologic relapse on portal pressures. Possible support for this proposal is provided by the changes in wedged hepatic vein pressure gradient in patients who relapse following antiviral therapy. ${ }^{4}$ Although comparison of pre- and posttreatment measurements was not provided, there appears to be an increase in the wedged hepatic venous gradient in patients who relapse versus no significant change in those who do not respond to antiviral therapy. Histologic findings of acute hepatitis $\mathrm{C}$ infection vary based on the timing. Early biopsies may show mixed cholestatic and portal/lobular inflammation, while late biopsies show milder nonspecific portal/lobular inflammation. ${ }^{20}$ Although ascites preceded the detection of relapse by 2 months in the second patient, a false negative test result due to a low viral load is possible. In addition, it has also been shown that in early relapse, HCV RNA may be detected in the liver before becoming detectable 
in the serum. ${ }^{8,9}$ We suspect that active hepatic inflammation contributing to increased portal pressures was present at the time ascites developed. We propose that the rapid improvement and ability to discontinue diuretic therapy the second case was a result of the spontaneous improvement in portal pressure due to decreased severity of inflammatory activity.

Although further studies are needed to confirm the association between virologic relapse and the development of ascites in a cirrhotic patient, our observation has potentially important implications. It highlights the importance of closely monitoring cirrhotic patients after completion of therapy and assessing for relapse in those who present with new-onset ascites. It also highlights the potential impact of active inflammation on the severity of portal hypertension. Finally, it raises the possibility that patients with decompensated cirrhosis due to $\mathrm{CHC}$ might clinically improve with effective antiviral therapy, as is the case with hepatitis B cirrhosis. This question will hopefully soon be addressed with the rapid improvement in interferon-free, direct-acting antiviral regimens.

\section{Author contributions}

Deborah Lim Chua - study concept and design, drafting of the manuscript, critically revised the manuscript and approved the final version. Thomas Hahambis - acquisition of data, critically revised the manuscript and approved the final version. Samuel Sigal - study concept and design, study supervision, critical revision of the manuscript for important intellectual content and approved the final version.

\section{Disclosure}

The authors report no conflicts of interest in this work.

\section{References}

1. Ward JW. The epidemiology of chronic hepatitis C and one-time hepatitis C virus testing of persons born during 1945 to 1965 in the United States. Clin Liver Dis. 2013;17(1):1-11.

2. Everson GT, Balart L, Lee SS, et al. Histological benefits of virological response to peginterferon alfa-2a monotherapy in patients with hepatitis $\mathrm{C}$ and advanced fibrosis or compensated cirrhosis. Aliment Pharmacol Ther. 2008;27(7):542-551.

3. Maylin S, Martinot-Peignoux M, Moucari R, et al. Eradication of hepatitis $\mathrm{C}$ virus in patients successfully treated for chronic hepatitis $\mathrm{C}$. Gastroenterology. 2008;135(3):821-829.

Hepatic Medicine: Evidence and Research

\section{Publish your work in this journal}

Hepatic Medicine: Evidence and Research is an international, peerreviewed, open access journal covering all aspects of adult and pediatric hepatology in the clinic and laboratory including the following topics: Pathology, pathophysiology of hepatic disease; Investigation and treatment of hepatic disease; Pharmacology of drugs used for
4. Roberts S, Gordon A, McLean C, et al. Effect of sustained viral response on hepatic venous pressure gradient in hepatitis C-related cirrhosis. Clin Gastroenterol Hepatol. 2007;5(8):932-937.

5. Bruno S, Crosignani A, Facciotto C, et al. Sustained virologic response prevents the development of esophageal varices in compensated, Child-Pugh class A hepatitis C virus-induced cirrhosis. A 12-year prospective follow-up study. Hepatology. 2010;51(6):2069-2076.

6. Cardoso AC, Moucari R, Figueiredo-Mendes C, et al. Impact of peginterferon and ribavirin therapy on hepatocellular carcinoma: incidence and survival in hepatitis $\mathrm{C}$ patients with advanced fibrosis. J Hepatol. 2010;52(5):652-657.

7. van der Meer AJ, Veldt BJ, Feld JJ, et al. Association between sustained virological response and all-cause mortality among patients with chronic hepatitis C and advanced hepatic fibrosis. JAMA. 2012;308(24): 2584-2593.

8. McHutchison JG, Poynard T, Esteban-Mur R, et al. Hepatic HCV RNA before and after treatment with interferon alone or combined with ribavirin. Hepatology. 2002;35(3):688-693.

9. Hara K, Rivera MM, Koh C, et al. Sequence analysis of the hepatitis C virus in relapse after sustained virological response: relapse or reinfection? J Infect Dis. Epub October 14, 2013.

10. Haber MM, West AB, Haber AD. Relationship of aminotransferases to liver histological status in chronic hepatitis C. Am J Gastroenterol. 1995;90(8):1250-1257.

11. Gelderblom HC, Zeuzem S, Weegink CJ, et al. Inflammatory markers neopterin and alanine aminotransferase in $\mathrm{HCV}$ patients treated with $\mathrm{HCV}$ NS3-4A protease inhibitor telaprevir (VX-950) and/or peginterferon alfa-2a. Scand J Gastroenterol. 2008;43(9):1122-1127.

12. Kim SU, Kim JK, Park YN, Han KH. Discordance between liver biopsy and Fibroscan in assessing liver fibrosis in chronic hepatitis B: risk factors and influence of necroinflammation. PLoS One. 2012;7(2):e32233.

13. Bureau C, Metivier S, Peron JM, et al. Transient elastography accurately predicts presence of significant portal hypertension in patients with chronic liver disease. Aliment Pharmacol Ther. 2008;27(12):1261-1268.

14. Poynard T, Degott C, Munoz C, Lebrec D. Relationship between degree of portal hypertension and liver histologic lesions in patients with alcoholic cirrhosis. Effect of acute alcoholic hepatitis on portal hypertension. Dig Dis Sci. 1987;32(4):337-343.

15. Kc S, Sharma D, Basnet BK, Mishra AK. Effect of acute hepatitis E infection in patients with liver cirrhosis. JNMA J Nepal Med Assoc. 2009;48(175):226-229.

16. Roche B, Samuel D. Antiviral therapy in HCV-infected cirrhotics awaiting liver transplantation: a costly strategy for mixed virological results. J Hepatol. 2009;50(4):652-654.

17. Afdhal N, Giannini EG, Sigal S, et al. Albumin and MELD score predict decompensation in patients with $\mathrm{HCV}$ cirrhosis and thrombocytopenia on interferon therapy: analysis from the ENABLE studies [abstract]. J Hepatol. 2012;56(1):995A.

18. Hezode C, Dorival C, Zoulim F, et al, for the CUPIC study group. Safety of telaprevir or boceprevir in combination with peginterferon alfa/ribavirin, in cirrhotic non responders. First results of the French early access program (ANRS CO20-CUPIC). J Hepatol. 2012;56 Suppl 2:S4.

19. Atkinson M, Losowsky MS. The mechanism of ascites formation in chronic liver disease. Q J Med. 1961;30:153-166.

20. Johnson K, Kotiesh A, Boitnott JK, Torbenson M. Histology of symptomatic acute hepatitis $\mathrm{C}$ infection in immunocompetent adults. $\mathrm{Am} J$ Surg Pathol. 2007;31(11):1754-1758.

the treatment of hepatic disease. Issues of patient safety and quality of care will also be considered. The manuscript management system is completely online and includes a very quick and fair peer-review system, which is all easy to use. Visit http://www.dovepress.com/ testimonials.php to read real quotes from published authors. 